\title{
Цитокины - место и значение в патогенезе ОРВИ и COVID-19
}

Н.И. Алешина, Ж.Б. Понежева, Е.Н. Лазарева, О.С. Астрина, В.В. Малеев, А.А.Плоскирева

Центральный НИИ Эпидемиологии Роспотребнадзора, Москва, Российская Федерация

Резюме. Цитокиновый шторм - это общий термин, применяемый к неадаптивному выбросу цитокинов в ответ на инфекцию и другие раздражители. Патогенез сложен, но включает потерю регуляторного контроля продукции провоспалительных цитокинов, как на локальном, так и на системном уровнях. Некоторые данные показывают, что во время эпидемии коронавирусной болезни 2019 (COVID-19) серьезное ухудшение у некоторых пациентов было тесно связано с нарушением регуляции и избыточным выделением цитокинов. В этой статье дается обзор того, что известно о механизме и стратегиях лечения воспалительного шторма, вызванного вирусом COVID-19.

Ключевые слова: цитокины, респираторные вирусы, коронавирус, COVID2019.

В настоящий момент в разгар пандемии короновирусной инфекции вызванной COVID-19 все мировые научные разработки нацелены на изучение, понимание патогенеза и поиска наилучших методов лечения. Однако исследования по COVID-19 только начинаются и могут быть не особенно достоверны в сложившихся условиях нагрузки на систему здравоохранения разных стран.

Высокие уровни экспрессии IL-1B, IFN-ү, IP-10 и белка 1 хемоаттрактанта моноцитов (МСР-1) были обнаружены у пациентов с COVID-19. Эти воспалительные цитокины могут активировать клеточный ответ Т-хелпер типа 1 (Th1). Активация Th1 является ключевым событием в активации специфического иммунитета. Однако, в отличие от пациентов с 
атипичной пневмонией, пациенты с COVID-19 также имеют повышенные уровни секретируемых клетками Th2 цитокинов (таких как IL-4 и IL-10), которые ингибируют воспалительный ответ. Уровни IL-2R и IL-6 в сыворотке у пациентов с COVID-19 положительно коррелируют с тяжестью заболевания. Другие исследования показали, что по сравнению с пациентами c COVID-19 из отделений общего профиля, пациенты в отделении интенсивной терапии демонстрируют повышенные сывороточные уровни гранулоцитарного колониестимулирующего фактора, IP-10, MCP-1, воспалительный белок-1А макрофагов, и TNF- $\alpha$. При этом цитокиновый шторм положительно коррелирует с тяжестью заболевания [1].

Цитокины являются центральными в патофизиологии COVID-19; в то время как некоторые из них являются нужными (интерферон I типа, интерлейкин-7), другие оказывают негативный эффект (интерлейкин-1ß, -6 и TNF- $\alpha$ ), особенно в контексте так называемой цитокиновой бури. Появилась еще одна характеристика этого заболевания: сопутствующий иммунодефицит, вызывающий ослабленную реакцию интерферона типа I и лимфопению. Дефектный ответ IFN типа I, роль IL-7 в восстановлении лимфоцитов, а так же наблюдающийся при тяжелом COVID-19 -синдром

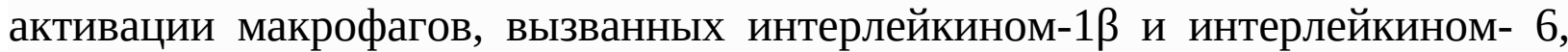
приводят к иммунной дисрегуляции [2].

Эпителиальные клетки дыхательных путей секретируют множество цитокинов, хемокинов, антимикробных пептидов и других факторов в ответ на вирусную инфекцию. Цитокины продуцируемые эпителием дыхательных путей, включают интерлейкин-6 (IL-6), фактор некроза опухоли- $\alpha$ (TNF- $\alpha$ ), гранулоцитарный колониестимулирующий фактор (G-CSF) и гранулоцитарный макрофаг-CSF (GM-CSF). IL-6 и TNF- $\alpha$ являются мощными провоспалительными цитокинами, которые модулируют многие типы иммунных клеток. IL-6 облегчает переход от врожденного к адаптивному иммунному ответу, снижая активность нейтрофилов, одновременно стимулируя рекрутирование, дифференцировку и активность 
моноцитов и T-клеток [3]. Высокие уровни IL-6 коррелируют с тяжестью заболевания, но устранение передачи сигналов IL-6 может привести к неконтролируемой репликации вируса, что приводит к большей смертности [4]. TNF- $\alpha$ ухудшает репликацию вируса, усиливает цитотоксическую активность и продукцию цитокинов лейкоцитами и активирует эндотелиальные клетки [5]. Повышенные уровни TNF- $\alpha$ были связаны с большей заболеваемостью во время инфицирования высокопатогенным вирусом, а блокирующая активность TNF- $\alpha$ ослабляет иммуноопосредованную патологию [4].

IP-10 / CXCL10 стимулирует хемотаксис T-клеток, NK-клеток и моноцитов в дополнение к стимулированию активации моноцитов и дендритных клеток совместно с другими цитокинами.CXCL10 / IP-10 может быть защитным в некоторых случаях, так как нейтрализация IP-10 ухудшает заболевание, вызываемое респираторной вирусной инфекцией [6]. В других случаях CXCL10 / IP-10 может способствовать обширному повреждению лейкоцитов, распространяя усиленный воспалительный ответ и иммуноопосредованное повреждение легких $[7,8]$.

В настоящее время известно, что эффективный иммунный ответ для устранения вирусных патогенов является существенным, длительный или преувеличенный ответ может повредить дыхательные пути. Таким образом, противовирусный иммунный ответ представляет собой баланс между элиминацией вируса и иммуноопосредованным легочным повреждением [9].

В совокупности дефицит HIF-1 $\alpha$ в эпителиальных клетках легких снижает гликолиз и усиливает аутофагию, что в конечном итоге облегчает репликацию вируса гриппа А. [10].

Данные Kim S и соавторов показывают, что IFN- $\lambda 2$ / 3-опосредованный врожденный иммунный ответ необходим для защиты легких от инфекции IAV , и интраназально доставленный IFN- $\lambda 2$ / 3 потенциально может быть полезной терапевтической стратегией для лечения гриппа А [11]. 
Ученые изучающие IL-10 установили, что его отсутствие во время первичной инфекции приводит к усилению локальной выработки антител, специфичных к вирусу, и, таким образом, к повышению защиты от инфекции вирусом гриппа А [12].

В тоже время вирус гриппа А подрывает антивирусную защиту хозяина, опосредованную IFN-гамма, посредством воздействия на внутриклеточные сигнальные пути. [13].

Эксперименты Longhi и соавторов показывают в течение периода острой инфекции цитопатическим вирусом критическую роль IL-6 в обеспечении того, что антигенспецифические Tregs не имеют возможности подавлять иммунный ответ, тем самым способствуя очистке от патогенов и выживанию хозяина [14].

IL-6, IL8, IL 15, MIP-1a, MIP-1b и TNF $\alpha$ являются потенциально хорошими маркерами для обнаружения доказанного сепсиса. В случае, если эти цитокины не повышены у больных детей, считают Lusyati S и соавторы, необходимо определить другие причины, помимо инфекции [15].

Активированные цитокины (IL-1, IL-2, IL-4, IL-8, IL-12p70, IL-17A, IFN-ү, IP-10, MIP-1b), идентифицированные в слезной жидкости и слюне пациентов с синдромом Шегрена, показывают четкую взаимосвязь между врожденными и адаптивными иммунными реакциями. Увеличение IP-10 и MIP как в слезах, так и в слюне дополнительно подчеркивает важную роль макрофагов и врожденного иммунитета при этом синдроме [16].

Онкологи, изучающие рак молочной железы выявили, что IP-10, IL-6, G-CSF, остеопонтин, MIP-1a, MIP-1b и MCP1-MCAF были выше в более агрессивных опухолях. [17].

Было обнаружено, что пациенты с раком уротелия имеют значительно высокие концентрации 12 мочевых цитокинов (IL-2, IL-4, IL-8, IL-10, GMCSF, IFN- $\gamma$, IP-10, MIP-1a, PDGF, MIP-1b , RANTES и VEGF) по сравнению со здоровыми контролями. Сыворотка VEGF и мочевой IL-1ra, IL-4, IL-10, GM-CSF, IP-10, Концентрации MIP-1a и MIP-1b были обнаружены 
значительно выше в концентрациях в опухолях высокой степени по сравнению с опухолями низкой степени. Плохая выживаемость также наблюдалась при увеличении количества цитокинов, демонстрирующих высокие концентрации. [18].

Papa A и Kotrotsiou $\mathrm{T}$ изучающих лептоспироз предполагают, что цитокины, продуцируемые в ответ на инфекцию патогенными лептоспирами, участвуют в патогенезе заболевания. Они выявили, что уровни IL-6, IL-8, GM-CSF, IP-10, MCP-1 и VEGF значительно отличались между тяжелыми случаями и контрольной группой, в то время как уровни GM-CSF значительно различались между легкими случаями и контролем группа (р <0,05).IL-6, IP-10 и MCP-1 были повышены в большинстве случаев.IP-10 был значительно выше в тяжелых, чем в не тяжелых случаях (p <0,05).Высокие уровни IP-10 предполагают клеточный иммунный ответ, несмотря на то, что лептоспиры не являются внутриклеточными организмами. Пик IL-1a, MCP-1, MIP-1b и TNF- $\alpha$ достиг пика через 1-5 дней после начала заболевания, IL-1b, IL-6, IL-8, IL-9, GM-CSF, IP- 10 и MIP-1а достигли максимума через 6-10 дней после восстановления, в то время как VEGF достиг максимума через 1115 дней после восстановления. TNF- $\alpha$ был значительно ниже в тяжелых случаях с поражением легких (p <0,05)[19].

Вышеприведенные данные носят порой противоречивый характер и требуют дальнейшего изучения. Однозначного взгляда на место определенных цитокинов в патогенезе ОРВИ, пневмоний и нового коронавируса на данный момент нет. Лучшее понимание иммунного ответа при COVID-19 может стать основой для иммунотерапевтических препаратов, особенно в тяжелых случаях.

Литература:

1. Ye Q, Wang B, Mao J.The pathogenesis and treatment of the 'Cytokine Storm' in COVID-19.J Infect. 2020 Jun;80(6):607-613. doi: 10.1016/j.jinf.2020.03.037. 
2. Jamilloux Y, Henry T, Belot A, Viel S, Fauter M, El Jammal T, Walzer T, François B, Sève P.Should we stimulate or suppress immune responses in COVID-19? Cytokine and anti-cytokine interventions. Autoimmun Rev. 2020 May 4:102567. doi: 10.1016/j.autrev.2020.102567. Online ahead of print.

3. Simon A. Jones, Directing Transition from Innate to Acquired Immunity: Defining a Role for IL-6J Immunol September 15, 2005, 175 3463-3468;

DOI: https://doi.org/10.4049/jimmunol.175.6.3463

4. John R Teijaro , The Role of Cytokine Responses During Influenza Virus Pathogenesis and Potential Therapeutic Options Curr Top Microbiol Immunol. 2015;386:3-22. doi: 10.1007/82_2014_411.

5. Takahiko Horiuchi, Hiroki Mitoma, Shin-ichi Harashima, Hiroshi Tsukamoto, Terufumi Shimoda Transmembrane TNF- $\alpha$ : structure, function and interaction with anti-TNF agents, Rheumatology, Volume 49, Issue 7, July 2010, Pages 1215-1228, https://doi.org/10.1093/rheumatology/keq031

6. Dennis M Lindell 1, Thomas E Lane, Nicholas W Lukacs. CXCL10/CXCR3-mediated Responses Promote Immunity to Respiratory Syncytial Virus Infection by Augmenting Dendritic Cell and CD8(+) T Cell Efficacy. Eur J Immunol. 2008 Aug;38(8):216879. doi: 10.1002/eji.200838155.

7. Akihiko Ichikawa 1, Keiji Kuba, Masayuki Morita, Shinsuke Chida, Hiroyuki Tezuka, Hiromitsu Hara, Takehiko Sasaki, Toshiaki Ohteki, V Marco Ranieri, Claudia C dos Santos, Yoshihiro Kawaoka, Shizuo Akira, Andrew D Luster, Bao Lu, Josef M Penninger, Stefan Uhlig, Arthur S Slutsky, Yumiko Imai CXCL10-CXCR3 Enhances the Development of Neutrophil-Mediated Fulminant Lung Injury of Viral and Nonviral Origin. Am J Respir Crit Care Med. 2013 Jan 1;187(1):65-77. doi: 10.1164/rccm.201203-0508OC. 
8. Wei Wang, Penghui Yang, Ying Zhong, Zhongpeng Zhao, Li Xing, Yan Zhao, Zhen Zou, Yanli Zhang, Chenggang Li, Taisheng Li, Chen Wang, Zhong Wang, Xuezhong Yu, Bin Cao, Xiang Gao, Josef $\mathrm{M}$ Penninger, Xiliang Wang, Chengyu Jiang Monoclonal Antibody Against CXCL-10/IP-10 Ameliorates Influenza A (H1N1) Virus Induced Acute Lung Injury Cell Res. 2013 Apr;23(4):577-80. doi: 10.1038/cr.2013.25.

9. Newton AH, Cardani A, Braciale TJ The host immune response in respiratory virus infection: balancing virus clearance and immunopathology.Semin Immunopathol. 2016 Jul;38(4):471-82. doi: 10.1007/s00281-016-0558-0.

10.Totura AL, Whitmore A, Agnihothram S, Schäfer A, Katze MG, Heise MT, Baric RS Toll-Like Receptor 3 Signaling via TRIF Contributes to a Protective Innate Immune Response to Severe Acute Respiratory Syndrome Coronavirus Infection. mBio. 2015 May 26;6(3):e00638-15. doi: 10.1128/mBio.00638-15

11. The Superiority of IFN- $\lambda$ as a Therapeutic Candidate to Control Acute Influenza Viral Lung Infection.Kim S, Kim MJ, Kim CH, Kang JW, Shin HK, Kim DY, Won TB, Han DH, Rhee CS, Yoon JH, Kim HJ.Am J Respir Cell Mol Biol. 2017 Feb;56(2):202-212. doi: 10.1165/ rcmb.2016-0174OC.

12.A detrimental effect of interleukin-10 on protective pulmonary humoral immunity during primary influenza A virus infection. Sun K, Torres L, Metzger DW.J Virol. 2010 May;84(10):5007-14. doi: 10.1128/JVI.02408-09.

13.Influenza A virus abrogates IFN-gamma response in respiratory epithelial cells by disruption of the Jak/Stat pathway.Uetani K, Hiroi M, Meguro T, Ogawa H, Kamisako T, Ohmori Y, Erzurum SC.Eur J Immunol. 2008 Jun;38(6):1559-73. doi: 10.1002/eji.200737045. 
14.Interleukin-6 is crucial for recall of influenza-specific memory CD4 T cells. Longhi MP, Wright K, Lauder SN, Nowell MA, Jones GW, Godkin AJ, Jones SA, Gallimore AM.PLoS Pathog. 2008 Feb 29;4(2):e1000006. doi: 10.1371/journal.ppat.1000006.

15.Cytokines patterns in newborn infants with late onset sepsis.Lusyati $\mathrm{S}$, Hulzebos CV, Zandvoort J, Sukandar H, Sauer PJ.J Neonatal Perinatal Med. 2013;6(2):153-63. doi: 10.3233/NPM-1364112.

16.Elevated cytokine levels in tears and saliva of patients with primary Sjögren's syndrome correlate with clinical ocular and oral manifestations.Chen X, Aqrawi LA, Utheim TP, Tashbayev B, Utheim ØA, Reppe S, Hove LH, Herlofson BB, Singh PB, Palm Ø, Galtung HK, Jensen JCL.Sci Rep. 2019 May 13;9(1):7319. doi: 10.1038/s41598-019-43714-5.

17.Wound Healing Fluid Reflects the Inflammatory Nature and Aggressiveness of Breast Tumors. Agresti R, Triulzi T, Sasso M, Ghirelli C, Aiello P, Rybinska I, Campiglio M, Sfondrini L, Tagliabue E, Bianchi F.Cells. 2019 Feb 19;8(2):181. doi: 10.3390/cells8020181.

18.Predictive role of serum and urinary cytokines in invasion and recurrence of bladder cancer. Kumari N, Agrawal U, Mishra AK, Kumar A, Vasudeva P, Mohanty NK, Saxena S.Tumour Biol. 2017 Apr;39(4):1010428317697552. doi: 10.1177/1010428317697552.

19.Cytokines in human leptospirosis. Papa A, Kotrotsiou T.Trans R Soc Trop Med Hyg. 2015 Dec;109(12):749-54. doi: 10.1093/trstmh/trv095.

Данные авторов:

Алешина Нина Игоревна, кандидат медицинских наук, старший научный сотрудник клинического отдела инфекционной патологии Центрального НИИ эпидемиологии Роспотребнадзора 
Адрес: 111123, Москва, ул. Новогиреевская, За

Телефон: (495) 365-0018

E-mail: nina_aleshina@list.ru

ORCID: https://orcid.org/0000-0001-5599-1970

Понежева Жанна Бетовна, доктор медицинских наук, заведующий клиническим отделом инфекционной патологии Центрального НИИ эпидемиологии Роспотребнадзора

Адрес: 111123, Москва, ул. Новогиреевская, За

Телефон: (495) 365-0018

E-mail: doktorim@mail.ru

ORCID: https://orcid.org/0000-0002-6539-4878

Лазарева Елена Николаевна, доктор медицинских наук, ведущий научный сотрудник клинического отдела инфекционной патологии Центрального НИИ Эпидемиологии Роспотребнадзора

Адрес: 111123, Москва, ул. Новогиреевская, За

Телефон: (495) 365-0018

E-mail: elniklazareva@yandex.ru

ORCID: https://orcid.org/0000-0003-1971-5535

Астрина Ольга Семеновна, кандидат биологических наук, старший научный сотрудник клинического отдела инфекционной патологии Центрального НИИ Эпидемиологии Роспотребнадзора

Адрес: 111123, Москва, ул. Новогиреевская, За

Телефон: (495) 365-0018

E-mail: o.astrina@mail.ru

ORCID: https://orcid.org/0000-0002-3820-2586 
Малеев Виктор Васильевич, академик РАН, доктор медицинских наук, профессор, советник директора по научной работе Центрального НИИ Эпидемиологии Роспотребнадзора

Адрес: 111123, Москва, ул. Новогиреевская, За

Телефон: (495) 974-9646

E-mail: maleyev@cmd.su

ORCID https://orcid.org/0000-0001-5748-178X

Плоскирева Антонина Александровна, д.м.н., доцент, заместитель директора по клинической работе ФБУН ЦНИИ эпидемиологии Роспотребнадзора

Адрес: 111123, Москва, ул. Новогиреевская, За

Телефон: (495) 6721136

e-mail: zdk@pcr.ru 